\title{
Bioactive Compounds in Peanuts and Banana
}

\author{
Bhat $\mathrm{EA}^{1 *}$, Sajjad N², Manzoor $\mathrm{I}^{2}$, Rasool A ${ }^{3}$
}

${ }^{1}$ Life Science Institute and School of Medicine, Zhejiang University, Hangzhou, Zhejiang, 310058, PR China; ${ }^{2}$ Department of Biochemistry, University of Kashmir, Hazratbal, Jammu and Kashmir, India; ${ }^{3}$ Department of Environmental Sciences, Osmania University, Hyderabad, India

\begin{abstract}
Bioactive compounds like carotenoids, phytosterols, flavonoids and phenolic acids have been identified in number of fruits and vegetables. But due to their less bioavailability owing to insolubility, their application in food industry is still unsuccessful. In this review, bioactive compounds present in bananas and peanuts and their potential health benefits are discussed. Peanuts possess many important compounds like resveratrol, phenolic acids, flavonoids and phytosterols which inhibit the absorption of cholesterol from diet. Moreover, it is also good source of Co-enzyme Q10 and contains all the 20 amino acids with highest content of arginine. Banana also contains various essential bioactive compounds such as phenolics, carotenoids, biogenic amines and phytosterols. Most of the compounds have been reported as potent antioxidants and are compelling in securing the body against different oxidative stress related conditions.
\end{abstract}

Keywords: Bioactive compounds; Peanuts; Bananas; Carotenoids; Phytosterols; Flavonoids; Phenolic acids

\section{INTRODUCTION}

Various bioactive components are present in different fruits, vegetables and nuts. They have been reported beneficial for human health. Furthermore, these compounds show different pharmacological activities such as antioxidant, anti-inflammatory, antibacterial, and immunomodulatory activities [1]. In view of customer contemplation and inclinations towards health friendly foods, the advancement of new functional foods is a leading trend in food industry. Numerous bioactive compounds have been derived from natural sources and categorized in different classes depending upon their structure like, phenolic compounds, vitamins, carotenoids, alkaloids, and organosulfur compounds $[2,3]$. They show various therapeutic effects. For example, allicin isolated from garlic, curcumin isolated from turmeric, catechins from polyphenols prevent our body from various diseases including cancer, cardiovascular ailment, neuronal degenerative illnesses, diabetes, and so forth $[4,5]$. In this review we examine the bioactive compounds present in peanuts and bananas and their potential health benefits.

\section{PEANUT AS A FUNCTIONAL FOOD}

Peanut is known as functional food. It consists of different functional components such as coenzyme Q10 which secures the heart amid absence of oxygen, for example at high altitudes and in case of clogged veins. Research has shown different compounds in peanuts and in their skin. They can possess various health benefits beyond basic nutrition. Moreover, peanuts act as efficient source of dietary fiber, and other essential nutrients that include few B complex group of vitamins, vitamin E, minerals, for example, iron, zinc, potassium and magnesium, and antioxidant minerals (selenium, manganese and copper). It also contains antioxidant compounds like flavonoids and resveratrol [6]. The antioxidant activity of peanut is because of vitamin E, caffeic, coumaric acid, flavonoids and stilbenes. These bioactive compounds possess preventative properties [7].

\section{HEALTH BENEFITS OF PEANUTS}

Apart from the everyday nutrition peanut utilization prompts long term health advantages. Peanuts have higher antioxidant property as compared to other foods like red wine, green tea etc. [8].

It has been reported that boiling increases the concentration of antioxidants in peanuts. Therefore, boiled peanuts contain higher content of isoflavones [9]. The skin of peanuts contains potent antioxidants. It has been demonstrated that peanuts taken with skin intact increases their antioxidant potential. Furthermore, roasting increase this limit too [7,9].

Correspondence to: Bhat EA, Life Science Institute and School of Medicine, Zhejiang University, Hangzhou, Zhejiang, 310058, PR China, Tel: +8613588249814; E-mail: eijazbhat05@gmail.com

Received: March 06, 2019; Accepted: April 15, 2019; Published: April 22, 2019

Citation: Bhat EA, Sajjad N, Manzoor I, Rasool A (2019) Bioactive Compounds in Peanuts and Banana. Biochem Anal Biochem 8:382. doi: 10.35248/2161-1009.19.8.382.

Copyright: (C) 2019 Bhat EA, et al. This is an open-access article distributed under the terms of the Creative Commons Attribution License, which permits unrestricted use, distribution, and reproduction in any medium, provided the original author and source are credited. 
The utilization of simple and processed peanuts has appeared to be helpful for human wellbeing, because of their attractive lipid profile, that is rich in unsaturated fats. Peanut oil is naturally transfat-free, cholesterol free, and low in saturated fats. It demonstrates many effects owing to its high content of oleic acid.

Various examinations have uncovered that utilization of peanuts or shelled nut oil is related with lessened cardiovascular sickness (CVD) hazard and may enhance serum lipid profiles, diminish LDL oxidation, and apply a cardio-defensive impact. Frequent intake of peanuts and its products may lessen the danger of colorectal tumor. A few people have hypersensitive responses to peanuts [10].

It has been investigated that peanut consumption lower the risk factors of various heart diseases, diabetes etc. [11]. Mortality due to cardiovascular diseases was decreased in people who consumed peanut or peanut butter daily [11]. Hypertension is related with higher risks of heart disease and stroke. Researchers have discovered that the dietary options we have, can affect the blood pressure. Peanuts and peanut butter contain monounsaturated fatty acids, plant proteins, magnesium, potassium, fiber, arginine and various bioactive components which help to lower the blood pressure. Peanut flour is used in composite flours with non-wheat cereals. It can improve the nutritional value of bread. Moreover, peanut products like peanut bars are consumed worldwide in many forms. Peanuts are good source of protein, fats, and fiber.

\section{BIOACTIVE COMPONENTS IN PEANUTS}

\section{Flavonoids and phenolic acids}

Flavonoids are present in peanut. They have been reported to prevent heart diseases by different mechanisms. Peanut and related products like peanut butter contain various kinds of flavonoids [12]. Research showed that peanuts and their skin contain functional compounds like phenolic acids. Various studies reported that peanuts possess high content of polyphenolic antioxidants, particularly in p-coumaric acid levels, which adds to its antioxidant content by as much as $22 \%$ [13]. It is also shown that roasted peanut skin possess higher antioxidant potential than roasted whole peanut.

\section{Arginine}

Arginine or L-arginine is an amino acid which is responsible for healthy liver, skin, joints, and muscles. Arginine reinforces the body's resistance framework, controls hormones and blood sugar level and advances male fertility. Research has reported that arginine may enhance circulation and treat impotency and heart related disease. Arginine is a semi-essential amino acid. Despite the fact that the body fabricates its own particular supply, sometimes dietary supplementation might be required, for example, on account of serious injuries or ailment. Arginine fortifies the resistance framework of the body by expanding the $\mathrm{T}$ lymphocytes ( $T$ cells) from the thymus gland. Various studies showed the role of arginine in treatment of various diseases like AIDS, cancer, and different infections. Furthermore, arginine is also involved in detoxification of liver by inhibiting the effects of ammonia and various other harmful substances in the body. Peanuts have the highest content of arginine among nourishment [14].

\section{Phytosterols}

Developing proof is demonstrating that phytosterols lower down inflammation process and decrease the growth of different cancers i.e. lung, stomach, ovarian, prostrate, colon and breast cancer [15]. Phytosterols also indicate the lowering of heart disease [16]. They are group of natural compounds found in plant cell membranes. It has been reported that it lower down the aggregate cholesterol up to $10 \%$ and LDL or "bad" cholesterol up to $14 \%$. Various studies also show that the reintroduction of plant foods giving phytosterols into the modern eating routine can enhance serum lipid (cholesterol) profiles and decrease the danger of cardiovascular infection [17].

\section{Banana}

The intake of fruits is important for well-being of humans. It cut down the risk of various chronic diseases, such as heart ailments, stroke, gastrointestinal disorders, certain types of cancers, hypertension, age-related macular degeneration, skin conditions, lowering of low-density lipoprotein (LDL) cholesterol, and improved immune function. Fruits contain excellent source of dietary fibres, vitamins, minerals and various phytochemicals. They possess potent antioxidant activity. Fruits form crucial part of daily diet. Fruits are categorized into temperate fruits, sub-tropical fruits, and tropical fruits. Banana comes under tropical fruits. Banana is reported to be rich in carbohydrates, dietary fibres, certain vitamins, and minerals.

\section{Bioactive compounds in banana}

Plant secondary metabolism constitutes bioactive compounds which possess various therapeutic potential [18]. Banana has number of bioactive compounds. It has higher antioxidant property owing to the bioactive constituents like phenolics, carotenoids, flavonoids and biogenic amines (Figures 1 and 2).

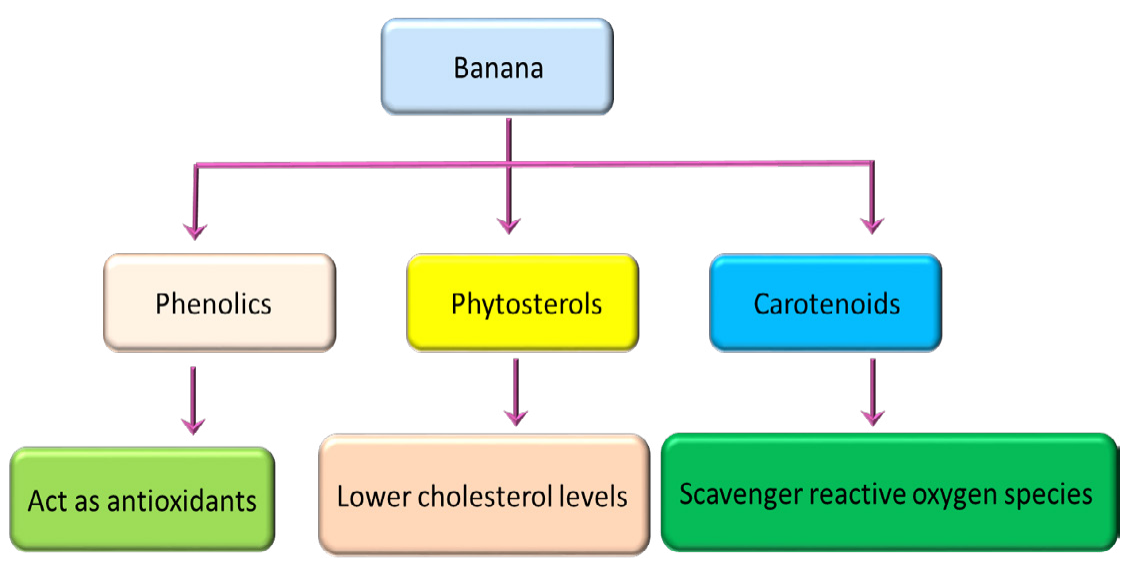

Figure 1: Bioactive compounds in Banana. 


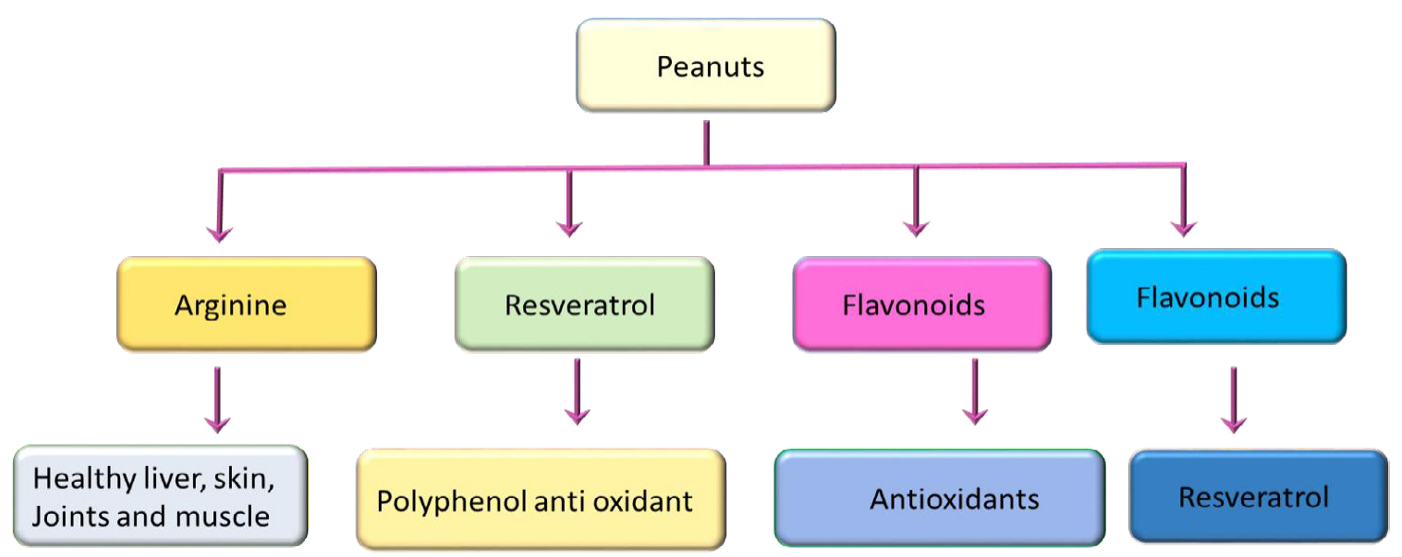

Figure 2: Bioactive compounds in Peanuts.

\section{Phytosterols}

Phytosterols are prescribed by doctor to lower the cholesterol [19]. They tend to bind with cholesterol and decrease its assimilation. Many studies have reported that banana possess various phytosterols [20,21]. $\beta$-Sitosterol, stigmasterol, campesterol, cycloeucalenol, cycloartenol, and 24-methylene cycloartenol were reported in banana peels [22]. Akihisa et al. [23] did a detailed investigation of sterol constituents of banana peels and reported new sterol (24S)-14 $\alpha$, 24-dimethyl-9 $\alpha$, 19-cyclo-5 $\alpha$-cholest-25-en-3 $\beta$ ol by chemical and spectroscopic methods. The dichloromethane extract of some fractions of Musa acuminate contains steryl glucosides namely stigmasteryl $3-\beta-$ d-glucopyranoside, campesteryl

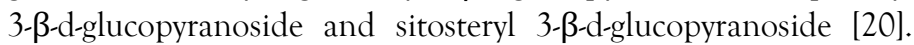
Villaverde et al. [21] identified phytosterols in banana cultivars. They were cycloeucalenone, cycloeucalenone, cycloeucalenol, cycloartenol, stigmasterol, campesterol and $\beta$-sitosterol. These constituents were present in unripe bananas. M. balbisiana cultivars, such as 'Dwarf Red' and 'Silver', have higher amounts of phytosterols than the M. acuminata. The main sterol present in lipophilic extracts of peels is Cycloeucalenone. Vilela et al. [24] studied chemical composition of the lipophilic extract of ripe pulp of banana fruits of several Musa species using GC-MS and identified phytosterol in the range of $11.1-28.0 \%$ of the total amount of lipophilic components.

\section{Carotenoids}

Carotenoids are beneficial to human health owing to their physiological properties. They are involved in scavenging of free radicals. They diminish the progression of diseases, especially certain tumors and eye illnesses. They are synthesized via isoprenoid biosynthetic pathway, with basic roles as antioxidants and accessory pigments for light harvesting in plants [25]. Englberger, Aalbersberg, et al. investigated raw and cooked samples of bananas, giant swamp taro, breadfruit cultivars and reported that banana cultivars has higher levels of carotenoids having $\beta$-carotene levels. Survey reported that the varieties of banana have been reported to possess higher levels of provitamin and total carotenoids. Consumption of foods which is rich in carotenoids improves immunity and lower the risk of diseases, such as cancer, diabetes and heart problems [26].

\section{Antioxidants}

The reactive oxygen species (ROS) plays an important role in progression of various diseases like arthritis, diabetes, arteriosclerosis, age-related macular degeneration, certain types of cancer, inflammation, genotoxicity, and alzheimer disease. Pazmino-Duran et al. [27] have reported the use of anthocyanins present in banana bracts (florets) as natural colorants. They reported various anthocyanins such as cyanidin-3-rutinoside and 3-rutinoside derivatives of delphinidin, pelargonidin, peonidin, and malvidin. Apart from banana pulp, pseudo stem and fruit peel of banana have been found to be the good sources of antioxidants. Many studies reported greater content of polyphenols, flavonoids, total dietary fibre, insoluble dietary fibre, lignin, hemicellulose, cellulose in banana. Pereira and Maraschin [28] and Singh et al. [29] have showed that banana contains many bioactive compounds, for example, carotenoids, flavonoids, phenolics, amines, vitamin $\mathrm{C}$, and vitamin $\mathrm{E}$ possessing high antioxidant activity $[30,31]$.

\section{CONCLUSION}

There is an awesome assorted variety of valuable bioactive compounds in bananas and peanuts. They contain various number of essential bioactive compounds beneficial for human health. Various studies have reported antioxidant activities of these compounds. They can therefore, used in prevention of diseases. Peanuts and banana cultivars contain huge number of these bioactive compounds should further be investigated. There is scope to commercialize peanut products owing to their beneficial uses. Moreover, there is need to spread awareness that peanut can prevent undesired supplementations. Bananas are grown and consumed worldwide. It is consumed in both raw as well as cooked form, because of their high nutritive and medicinal value. There is need for further research to explore and utilize natural antioxidants and dietary fiber present in banana peel for health benefits. Various studies have reported high content of essential bioactive compounds in banana peel than pulp which could be utilized as functional food source against many chronic diseases.

\section{DECLARATION}

\section{Ethics approval and consent to participate}

This article does not contain any studies with human participants or animals performed by any of the authors.

\section{Consent for publication}

Not applicable. 


\section{Availability of data and materials}

The datasets used in the current study are available from the corresponding author by request.

\section{Competing interest}

The authors have no personal or financial conflicts of interest associated with this work.

\section{Funding}

Not applicable.

\section{REFERENCES}

1. Hsieh YS, Yang SF, Sethi G, Hu DN. Natural bioactives in cancer treatment and prevention. Biomed Res Int. 2015:182835.

2. Jeong JY, Park MN, Cho ES, Jang HJ, Park SK, Lee HJ. Epigallocatechin-3-gallate-induced free-radical production upon adipogenic differentiation in bovine bone-marrow mesenchymal stem cells. Cell Tissue Res. 2015;362:87-96.

3. Lim J, Jeong S, Lee J, Park S, Lee J, Lee S. Effect of shortening replacement with oleogels on the rheological and tomographic characteristics of aerated baked goods. J Sci Food Agric. 2017;97:37273732 .

4. Pandey KB, Rizvi SI. Plant polyphenols as dietary antioxidants in human health and disease. Oxid Med Cell Longev. 2009;2:270-278.

5. Pham-Huy LA, He H, Pham-Huy C. Free radicals, antioxidants in disease and health. Int J Biomed Sci. 2008;4:89-96.

6. Geulein I. Antioxidant properties of resveratrol: a structure activity insight. Innov Food Sci Emerg Technol. 2010;11:210-218.

7. Yu J, Ahmedna M, Goktepe I, Dai J. Peanut skin procyanidins: composition and antioxidant activities as affected by processing. J Food Compos Anal. 2006;19:364-371.

8. Halvorsen BL, Carlsen MH, Philips KM, Bohn SK, Holte K, Jacobs DR, et al. Content of redox-active compounds (i.e. antioxidants) in foods consumed in the United States. Am J Clin Nutr. 2006;84:95-135.

9. Craft BD, Hargrove JL, Greenspan P, Hartle DK, Amarowicz R. Recent Advances in food and flavor chemistry. Food flavor and encapsulation, health benefits, analytical methods, and molecular biology of functional foods, Cambridge, UK: R Soc Chem. 2010;283-296.

10. Woodroof JG. Historical background in Peanuts: production, processing, products, AVI Westport CT 181. 1983.

11. Fraser GE, Sabate J, Beeson WL, Strathan TM. A possible protective effect of nut consumption on risk of CHD. Arch Intern Med. 1992;152:1416-1424.

12. Francisco ML, Resurreccion AV. Functional components in peanuts. Crit Rev Food Sci Nutr. 2008;48:715-746.

13. Duncan CE, Gorbet DW, Talcott ST. Phytochemical content and antioxidant capacity of water-soluble isolates from peanuts (Arachis hypogaea L.). Food Res Int. 2006;39:898-904.

14. Moncada S, Higgs A. The L-arginine-nitric oxide pathway. N Engl J Med. 1993;329:2002-2012.
15. Woyengo TA, Ramprasath VR, Jones PJ. Anticancer effects of phytosterols. Eur J Clin Nutr. 2006;63:813-820.

16. Awad AB, Chan KC, Downie AC, Fink CS. Peanuts as a source of $\beta$-sitosterol, a sterol with anticancer properties. Nutr Cancer. $2000 ; 36: 238-241$.

17. Lopes RM, Agostini-Costa TDS, Gimenes MA, Silveira D. Chemical composition and biological activities of Arachis species. J Agric Food Chem. 2011;59:4321-4330.

18. Singh JP, Kaur A, Shevkani K, Singh N. Influence of jambolan (Syzygium cumini) and xanthan gum incorporation on the physicochemical, antioxidant and sensory properties of gluten-free eggless rice muffins. Int J Food Sci Technology. 2015;50:1190-1197.

19. Ostlund RE, Racette SB, Stenson WF. Inhibition of cholesterol absorption by phytosterol-replete wheat germ compared with phytosteroldepleted wheat germ. Am J Clin Nutr. 2003;77:1385-1389.

20. Oliveira L, Freire CSR, Silvestre AJD, Cordeiro N, Torres IC, Evtuguin D. Lipophilic extractives from different morphological parts of banana plant "Dwarf Cavendish". Industrial Crops and Products. 2006;23: 201-211.

21. Villaverde JJ, Oliveira L, Vilela C, Domingues RM, Freitas N, Nereida $\mathrm{C}$, et al. High valuable compounds from the unripe peel of several Musa species cultivated in Madeira Island (Portugal). Industrial Crops and Products. 2013;42:507-512.

22. Knapp FF, Nicholas HJ. The sterols and triterpenes of banana peel. Phytochemistry. 1969;8:207-214.

23. Akihisa T, Shimizu N, Tamura T, Matsumoto T. ((24S)-14a, 24-Dimethyl-9b, 19-cyclo-5a-cholest-25-en-3b-ol: A new sterol and other sterols in Musa sapientum. Lipids. 1986;21:494-497.

24. Vilela C, Santos SA, Villaverde JJ, Oliveira L, Nunes A, Cordeiro N, et al. Lipophilic phytochemicals from banana fruits of several Musa species. Food Chem. 2014;162:247-252.

25. Van den Berg H, Faulks R, Granado HF, Hirschberg J, Olmedilla B, Sandmann S, et al. The potential for the improvement of carotenoid levels in foods and the likely systemic effects. J Sci Food Agric. 2000;80:880-912.

26. Krinsky NI, Johnson EJ. Carotenoid actions and their relation to health and disease. Mol Aspects Med. 2005;26:459-516.

27. Pazmino-Duran EA, Giusti MM, Wrolstad RE, Gloria MBA. Anthocyanins from banana bracts (Musa x paradisiaca) as potential food colorants. Food Chem. 2001;73:327-332.

28. Pereira A, Maraschin M. Banana (Musa spp) from peel to pulp: ethnopharmacology, source of bioactive compounds and its relevance for human health. J Ethnopharmacol. 2015;160:149-163.

29. Singh B, Singh JP, Kaur A, Singh N. Bioactive compounds in banana and their associated health benefits-A review. Food Chem. 2016;206:1-11.

30. Duggan C, Gannon J, Walker WA. Protective nutrient and functional foods for the gastrointestinal tract 1-3. Am J Clin Nutr. 2002;75:789-808.

31. Oliveira L, Freire CS, Silvestre AJ, Cordeiro N. Lipophilic extracts from banana fruit residues: A source of valuable phytosterols. J Agric Food Chem. 2008;56:9520-9524. 